\title{
Radioimmunotherapy for Non-Hodgkin's Lymphoma
}

\author{
Arati V. Rao, MD, Gamal Akabani, PhD, and David A. Rizzieri, MD
}

\begin{abstract}
Non-Hodgkin's lymphoma (NHL) is the most common hematological malignancy in the United States with a rapidly increasing incidence. Most follicular NHL is indolent but incurable, whereas the more aggressive varieties do respond to therapy. Most patients with follicular NHL who transform to an aggressive NHL are very difficult to treat successfully. Treatment options have included chemotherapy, radiation, immunotherapy with monoclonal antibodies, alone or in combination, and hematopoietic stem cell transplantation. The efficacy of monoclonal antibodies is augmented when they are combined with a radioisotope like iodine- $13 \mid$ or yttrium-90. There have been a number of studies done in recent years studying the efficacy of this form of therapy, i.e., radioimmunotherapy (RIT) in patients with NHL. This review attempts to integrate the information from the various clinical trials done using RIT in patients with relapsed/refractory or newly diagnosed NHL and in hematopoietic stem cell transplantation. It also includes updates on the use of RIT in elderly patients and in patients with significant bone marrow involvement among other recent advances made in this field.
\end{abstract}

Keywords: Non-Hodgkin’s lymphoma; Radioimmunotherapy; Hematological malignancy; Monoclonal antibodies; Clinical trial

$\mathrm{N}$ on-Hodgkin's lymphoma (NHL) is the most commonly occurring hematologic malignancy in the United States with an estimated 54,370 new cases diagnosed in the year 2004. ${ }^{1}$ Notably, $85 \%$ of NHLs are B cell lymphomas and the most commonly occurring varieties include the diffuse B cell large cell lymphomas. Follicular lymphoma is the second most common type of NHL including $35 \%$ to $40 \%$ of all adult lymphomas. ${ }^{2}$ It is especially common in the elderly and is characterized by advanced stage at presentation and an indolent clinical course with a long median survival of 8 to 10 years. While patients might initially respond to therapy, the disease is punctuated by multiple episodes of recurrence leading ultimately to death due to refractory disease, transformation to an aggressive large B cell pathology or complications of therapy. Once transformation occurs, the median survival is $<1$ year. There are multiple chemotherapeutic options available for recurrence but none have had a significant impact on survival. More recently, radioimmunotherapy (RIT), which uses a monoclonal antibody in addition to a radionuclide to deliver radiation to the sites of disease, has been extensively studied in this population with encouraging results.
Reprint Requests: Arati V. Rao, MD, Division of Medical Oncology and Division of Geriatrics, Duke University Medical Center and Durham Veterans Affairs Medical Center, 508 Fulton Street, Durham, NC 27710;

Tel: 919-286-6944; Fax: 919-286-6896; Email: rao000I2@mc.duke.edu.

\section{Principles and Advantages of RIT}

There are several advantages to using RIT for the treatment of lymphoma. ${ }^{3}$ First, lymphomas are very sensitive to radiation in a dose-dependent fashion, thus making them ideal targets for RIT. Secondly, there are abundant and well characterized cell surface antigens overexpressed on the tumor cells, such as CD20. Thirdly, radioimmunoconjugates kill lymphoma cells predominantly by radioactive emissions and thus can be useful even when the patient has failed treatment with unmodified monoclonal antibodies. ${ }^{4}$ The $\beta$-particles emitted by the radioactive moieties in clinical use today, iodine-131 ( $\left.{ }^{131} \mathrm{I}\right)$ and yttrium-90 $\left({ }^{90} \mathrm{Y}\right)$, are cytotoxic. Particles are cytotoxic over a spherical volume with a radius that extends a few millimeters. The $\mathrm{R}_{90}$ of ${ }^{90} \mathrm{Y}$ is $5.3 \mathrm{~mm}$ and that of ${ }^{131} \mathrm{I}$ is $0.8 \mathrm{~mm}$ (maximum of $11.0 \mathrm{~mm}$ and 2.9 $\mathrm{mm}$, respectively). By targeting several tumor cells, tumor volumes of several centimeters can be efficiently treated by means of the "crossfire" effect. ${ }^{5}$ This also allows killing of tumor cells that may be inaccessible to an unmodified monoclonal antibody such as rituximab due to penetration barriers. It should not be overlooked that presently available agents for use in lymphoma ${ }^{90}$ Y-ibritumomab tiuxetan [Zevalin] and ${ }^{131}$ I-tositumomab [Bexxar]) are both given

Received: November 18, 2005

Revised: March 3I, 2005

Accepted: June 3, 2005 
with a naked antibody with anti-tumor effects of its own, preceding the radiolabeled dosage.

\section{Cellular Targets}

The CD20 antigen is a pan B cell antigen, which is homogenously expressed on more than $90 \%$ of B cell lymphomas at a density of 50,000 to 200,000 molecules/lymphoma cell. ${ }^{6}$ As a differentiation antigen, it is not expressed on stem cells, plasma cells or non-hematopoietic tissues. Since this antigen is minimally shed into the circulation in follicular or diffuse lymphoma, there is very little free antigen that would block the delivery of anti-CD20 antibody to the nodal areas of disease. CD20 is also minimally modulated or internalized after antibody binding. Anti-CD20 monoclonal antibodies are capable of directly killing cells by both complement-mediated effects (in vivo antibodies against CD55, e.g., decay accelerating factor and CD59 or protectin) and by antibody dependent cellular cytotoxicity, although there is also a direct effect - inhibition of cell proliferation by induction of apoptosis. Other antigenic targets on B cells or cells under investigation for targeted therapy include CD19, CD22, CD37, CD25, CD52 and HLA class II. CD19 is ubiquitously expressed on B cells, but is rapidly internalized after antibody binding.7,8 CD22 is expressed on $75 \%$ to $80 \%$ of $\mathrm{B}$ cell lymphomas, but is more variably expressed from cell to cell than CD19 or CD20, and is rapidly internalized after antibody binding. ${ }^{9}$ CD37 is present in high density on most B lymphocytes and is internalized to a moderate degree. However, previous studies have shown less favorable responses with anti-CD37 conjugates than with anti-CD20 radioimmunoconjugates. ${ }^{10}$ Thus, at this time, the most widely employed monoclonal antibody for lymphoma, Rituximab, targets CD20 and has been studied as a single agent and in combination with chemotherapy. However, all tumor cells may not be bound by monoclonal antibodies and might be resistant to its anti-tumor and immune activating mechanisms.

\section{Principles of RIT}

Conventional external beam radiotherapy delivers radiation at relatively high dose rates for short periods of time which are separated by intervals of hours or days during which no radiation is received. Tumor cells exposed to continuous external radiation are blocked from progressing past the G2 phase of the cell cycle. G2/M is the most radiosensitive part of the cell cycle and accumulation of cells at this stage is thought to increase the cytotoxicity of continuous low doses of radiation. In contrast, RIT delivers total body radiation in a more directed fashion with more focus on the actual tumor tissue than uninvolved normal viscera. Here, the peak dose rate is generally lower, but radiation is delivered continuously at an exponentially declining rate for days or weeks as the bound radioisotope decays within the tumor. Also, the continuous delivery of radiation by RIT may prevent cellular DNA repair from occurring.
In general, the terms and definitions for other radiotherapy or nuclear medicine techniques still apply with this method of delivering radiation. The total body residence time or clearance rate of the radioisotope depends upon size of the tumor, splenomegaly and bone marrow involvement. The administered dose is the therapeutic amount of radioactivity administered to a patient and is measured in $\mathrm{mCi}$ (or $\mathrm{MBq}$ ). The absorbed dose is the radiation to the tissue (tumor or organ) or total body and is measured in cGy. The process of relating the administered dose of radioactivity to the absorbed dose of radiation to the tissue is called dosimetry. ${ }^{11}$

\section{General Treatment Schema}

Strict release criteria for patient and staff safety must be maintained for the safe administration of RITs used to treat lymphoma today. Patients should have adequate marrow reserves with a near normal hemogram and $<25 \%$ marrow involvement with disease ( $<10 \%$ if only sampled unilaterally) The RIT therapeutic regimen for the presently available agents in NHL is delivered in two sets of intravenous infusions given 7 to 14 days apart. Nonradioactive antibody is given before both the "dosimetric" infusion and the "therapeutic" infusion to protect normal visceral sites from binding of the radioactive moiety and improve distribution of the radioactive doses to the tumor sites throughout the body. Within a couple hours of infusion of the nonradioactive dose (tositumomab for Bexxar or rituximab for Zevalin), a trace amount of radioisotope bound to an anti-CD20 antibody is initially given to enable physicians to evaluate the clearance of radiation from the patient's body with gamma camera scans (131I for Bexxar or indium-111 [ [111 In] for Zevalin). These scans allow evaluation to ensure that abnormal or altered distribution to the marrow, spleen, brain, lungs or other organs is not occurring and that proceeding with the larger 'therapeutic dose' would be considered safe.

The 'therapeutic dose' follows this 'dosimetric dose' 7 to 14 days later. In the case of ${ }^{131}$ I-tositumomab therapy, factors affecting clearance of the antibody include tumor size, splenomegaly and bone marrow involvement leading to a 4-fold variation in effective half-life of ${ }^{131}$ I-tositumomab. Therefore, the dosimetric scans are utilized to determine the dose of ${ }^{131}$ I to be bound with the tositumomab specifically calculated for the individual patient to deliver a target dose of 75 cGy total body exposure (65 cGy if the platelets are $100,000 / \mathrm{L}$ to $150,000 / \mathrm{L}$ rather than $>150,000 / \mathrm{L})$. In the case of therapy with ${ }^{90}$ Y-ibritumomab tiuxetan, if the dosimetric scans do not show altered biodistribution then a weight-based constant dose of ${ }^{90} \mathrm{Y}$-ibritumomab tiuxetan of $0.4 \mathrm{mCi} / \mathrm{kg}$ to a maximum of $32 \mathrm{mCi}$ is delivered to the patient $(0.3 \mathrm{mCi} / \mathrm{kg}$ if the platelets are $100,000 / \mathrm{L}$ to $150,000 / \mathrm{L})$.

\section{${ }^{131}$ I-tositumomab}

Tositumomab is a murine immunoglobulin G2a anti-B1 antibody that targets CD20 and is covalently bound to ${ }^{131} \mathrm{I}$ as the active radiolabeled moiety. ${ }^{12}$ Widely used for over 50 years, ${ }^{131} \mathrm{I}$ is relatively inexpensive, widely accessible, easily 
Table 1. Differences between ${ }^{131} \mid$-tositumomab and 90 Y-ibritumomab tiuxetan

\begin{tabular}{lll}
\hline Property & 131I-tositumomab & 90Y-ibritumomab tiuxetan \\
\hline Antibody & Murine, anti-CD20 & Murine, anti-CD20 \\
Dosing determination & $\begin{array}{l}\text { After dosimetry to ensure safe } \\
\text { target total body exposure }\end{array}$ & $\begin{array}{l}\text { Fixed dose or per } \\
\text { body weight }\end{array}$ \\
Radiation absorbed in normal tissue & Yes, particularly the thyroid & Yes, particularly marrow and liver \\
Pre-dosing with naked antibody & Yes & Yes \\
Radioisotope - radiation & lodine-131 emitting $\gamma$ and $\beta$ radiation & Ytrium-90 emitting $\beta$ radiation \\
Target & CD20 receptor on mature B cells & CD20 receptor on mature B cells \\
Radioisotope $1 / 2$ life & 8 days & 2.7 days \\
\hline
\end{tabular}

conjugated and can be used for both imaging and treatment (has both gamma and beta emissions). The $\beta$-particles have a half-life of 8 days and a short path length. Unfortunately, the ${ }^{131}$ I conjugates are rapidly degraded and released into the circulation with partial elimination in the gastrointestinal tract and urine. Exposure in this way to the $\gamma$ rays emitted by ${ }^{131}$ I can present a potential radiation hazard for family members and health care providers requiring careful precautions to be followed for at least 2 weeks after treatment. A study done at the University of Nebraska evaluated the amount of radiation exposure to family members from patients treated with ${ }^{131}$ I-tositumomab. ${ }^{13}$ Twenty-six family members of the 22 patients treated were provided radiation-monitoring devices to directly monitor radiation exposure. Measured doses ranged from 10 to 409 mrem. In this and other studies, estimated and measured dose equivalents to maximally exposed individuals were below $500 \mathrm{mrem}$ (the nuclear regulatory commission threshold for safe annual exposure). Therefore, RIT with tositumomab and ${ }^{131}$ I-tositumomab can be safely conducted on an outpatient basis in most states with certain precautions for 2 weeks following therapy. In general, these precautions include maintaining a safe distance of at least 6 feet, when possible, from others (particularly children and pregnant or nursing mothers), abstaining from intercourse, using a separate bathroom, bagging all clothing and washing them separately from other members of the family, using a separate set of dishware and washing it separately, eliminating wastes while sitting at all times and flushing at least 2 times with the seat down and throwing away the toothbrush used after 2 weeks.

\section{${ }^{90}$ Y-ibritumomab tiuxetan}

Ibritumomab is a murine antibody chemically linked to tiuxetan which chelates ${ }^{111} \mathrm{In}$ for imaging and ${ }^{90} \mathrm{Y}$ for therapy. ${ }^{14}$ The active radioactive moiety in Zevalin is ${ }^{90} \mathrm{Y}$ which emits $\beta$-particles that are 5 times more energetic than ${ }^{131} \mathrm{I}$ and has potentially better tumor mass penetration. ${ }^{90} \mathrm{Y}$ has a half-life of 2.7 days and can be administered on an outpatient basis as well. ${ }^{90} \mathrm{Y}$ is stably retained by the tumor cells even after degradation, but does not emit $\gamma$ rays and thus cannot be used for imaging (dosimetry). For this reason, ${ }^{111}$ In is very similar to ${ }^{90} \mathrm{Y}$ in its radiochemistry and is used as a surrogate radioisotope for imaging purposes. ${ }^{90} \mathrm{Y}$ is generally more expensive and more difficult to obtain than ${ }^{131} \mathrm{I}$. However, recent efforts have improved drug availability. Unlike ${ }^{131} \mathrm{I}$, there is little excretion of the agent in the gastric contents or urinary system leading to the conclusion that safe outpatient administration and follow-up can be managed by following standard universal precautions.

\section{Other Radioisotopes}

There are other $\beta$-emitting isotopes such as copper-67, lutetium-177, rhenium-186 (186Re) and rhenium-188 which may be superior to ${ }^{131} \mathrm{I}$ and ${ }^{90} \mathrm{Y}$ for anti-tumor benefits, but their use is limited to very few centers..$^{15}$ Actinium-22516 and Bismuth-21217 emit dense $\alpha$-particles that confer much higher energy and have a potentially significant increased ability to eradicate tumor masses, but their short half-lives, difficult radiochemistry and toxicity to non-target tissues have, to date, restrict their use. ${ }^{125} \mathrm{I},{ }^{123} \mathrm{I}$, and ${ }^{111} \mathrm{In}$ emit Auger particles which need to penetrate the cell nucleus in order to cause DNA strand breaks. However, these Auger particles have the shortest range of energy deposition making it very difficult to exert their maximal effect. ${ }^{18}$ These alternative radiolabel moieties hold significant promise for future exploration.

\section{Results for $131 \mathrm{I}$-tositumomab and 90 Y-ibritumomab tiuxetan in Relapsed/Refractory Low- and Intermediate- Grade NHL}

\section{${ }^{131}$ I-tositumomab}

A series of clinical trials have established the efficacy of ${ }^{131}$ I-tositumomab in patients with relapsed or chemotherapy/rituxan refractory follicular lymphoma with doses of radiation that allowed safe recovery for the vast majority of patients, if the selection criteria noted above are followed. Kaminski et al. ${ }^{19}$ conducted a phase I/II study on 59 patients with relapsed/refractory follicular lymphoma. Forty-two (71\%) of 59 patients responded; 20 (34\%) had complete responses (CR) and $22(36 \%)$ had partial responses (PR). Response rates were higher $(83 \%)$ with low-grade or transformed NHL versus $(41 \%)$ with de novo intermediate-grade NHL $(P=0.005)$. For all 42 responders, the median progression-free survival was 12 months, 20.3 months for those with CR. Reversible hematologic toxicity was dose limiting. Five patients developed elevated thyroid-stimulating 


\begin{tabular}{|c|c|c|c|}
\hline Investigator & Patients/Prior Therapy & Percent CR & Percent PR \\
\hline \multicolumn{4}{|c|}{${ }^{90}$ Y-ibritumomab tiuxetan } \\
\hline Knox $1996^{22}$ & $18 /+$ & 34 & 38 \\
\hline Witzig 199923 & $51 /+$ & 26 & 41 \\
\hline Witzig $2002^{24}$ & $57 /+$ & 15 & 59 \\
\hline Witzig $2002^{25}$ & $143 /+$ & 30 & 50 \\
\hline \multicolumn{4}{|l|}{ 131I-tositumomab } \\
\hline Kaminski $2000^{19}$ & $59 /+$ & 34 & 36 \\
\hline Vose $2000^{20}$ & $47 /+$ & 32 & 25 \\
\hline Kaminski $2001^{21}$ & $60 /+$ & 20 & 45 \\
\hline
\end{tabular}

$\mathrm{CR}$, complete response; $\mathrm{PR}$, partial response; + , received prior therapy

hormone levels, five were diagnosed with myelodysplasia and three with solid tumors. This was followed by a phase II trial by Vose et al. ${ }^{20}$ in which 27 of the 47 patients (57\%) treated with a single dosimetric and therapeutic dose had a response. The response rate was similar in patients with low-grade $(57 \%)$ or transformed low-grade $(60 \%)$ NHL. The median duration of response was 9.9 months. Treatment was well tolerated with the principal toxicity being hematologic. The most common non-hematologic toxicities related to the treatment included mild to moderate fatigue (32\%), nausea $(30 \%)$, fever $(26 \%)$, vomiting $(15 \%)$, infection $(13 \%)$, pruritus $(13 \%)$ and rash $(13 \%)$.

Kaminski et al. ${ }^{21}$ conducted a study on 60 patients with relapsed disease refractory to chemotherapy. A PR or CR was observed in 39 patients $(65 \%)$ after ${ }^{131}$ I-tositumomab compared with 17 patients $(28 \%)$ after their last qualifying chemotherapy $(P<0.001)$. The median duration of response was 6.5 months after ${ }^{131} \mathrm{I}$-tositumomab compared with 3.4 months after the chemotherapy $(P<0.001)$. This study demonstrated that a single course of ${ }^{131}$ I-tositumomab was significantly more efficacious than the chemotherapy.

\section{${ }^{90}$ Y-ibritumomab tiuxetan}

A phase I/II dose escalation study by Knox et al. ${ }^{22}$ utilizing ${ }^{90}$ Y-ibritumomab tiuxetan in 18 patients with recurrent B cell lymphoma demonstrated an overall response rate of $72 \%$ (six CR and seven PR) following a single dose of the drug. The time to tumor progression was 3 months to $\geq 29$ months. Non-hematologic toxicity was minimal but grade IV myelosuppression was evident at doses above $50 \mathrm{mCi}$. Witzig et $\mathrm{al} .{ }^{23}$ subsequently performed a phase I/II trial in 51 patients with relapsed or refractory NHL. The overall response rate was $67 \%$ (26\% CR, $41 \%$ PR) with higher responses in low-grade NHL, $82 \%$ versus $43 \%$ for intermediate-grade disease, and $0 \%$ for mantle-cell disease. Time to tumor progression in responders and duration of response is $\geq 12.9$ months and $\geq 11.7$ months, respectively. Adverse events were primarily hematologic and correlated with baseline extent of marrow involvement and baseline platelet count. This was followed by a study in rituximab-refractory follicular lymphoma in which 57 patients, all of whom were extensively pretreated, were enrolled. ${ }^{24}$ The overall response rate for 54 patients with follicular NHL was $74 \%$ ( $15 \% \mathrm{CR}, 59 \% \mathrm{PR})$. The time to tumor progression was 6.8 months for all patients and 8.7 months for responders. Adverse events were primarily hematologic. The incidence of grade 4 neutropenia, thrombocytopenia and anemia was $35 \%, 9 \%$ and $4 \%$, respectively. This group also conducted a phase III randomized study comparing ${ }^{90}$ Y-ibritumomab tiuxetan with rituximab in 143 patients with relapsed or refractory low-grade, follicular, or transformed CD20+ transformed NHL. ${ }^{25}$ Patients received either a single intravenous dose of ${ }^{90}$ Y-ibritumomab tiuxetan $0.4 \mathrm{mCi} / \mathrm{kg}(\mathrm{n}=73)$ or rituximab $375 \mathrm{mg} / \mathrm{m}^{2}$ intravenously weekly for 4 doses $(\mathrm{n}=70)$. Patients in the RIT group were pretreated with two rituximab doses $\left(250 \mathrm{mg} / \mathrm{m}^{2}\right)$ to improve biodistribution and one dose of ${ }^{111}$ In-ibritumomab tiuxetan for imaging and dosimetry. The overall response rate was $80 \%$ for the ${ }^{90} \mathrm{Y}$-ibritumomab tiuxetan group versus $56 \%$ for the rituximab group $(P=0.002)$. $\mathrm{CR}$ rates were $30 \%$ and $16 \%$ in the ${ }^{90} \mathrm{Y}$-ibritumomab tiuxetan and rituximab groups, respectively $(P=0.04)$. Median duration of response was 14.2 months versus 12.1 months in the control group $(P=0.6)$ and time to tumor progression was 11.2 versus 10.1 months $(P=0.173)$ in all patients. Reversible myelosuppression was the primary toxicity noted with ${ }^{90}$ Y-ibritumomab tiuxetan. Thus, treatment with RIT resulted in higher CR and overall response rate, but did not increase overall survival or event free survival.

\section{Results for $131 \mathrm{I}$-tositumomab and 90 Y-ibritumomab tiuxetan in Previously Untreated Low- to Intermediate- Grade NHL \\ ${ }^{131}$ I-tositumomab}

There have been three recent studies conducted in previously untreated low- to intermediate-grade NHL in which patients were treated with ${ }^{131}$ I-tositumomab immediately after completion of systemic chemotherapy either with 
cyclophosphamide-adriamycin-Oncovin-prednisone (CHOP), cyclophosphamide-vincristine-prednisolone (CVP) or with fludarabine. In all these studies, patients achieved very high overall response rates ( $80 \%$ to $100 \%$ ) with minimal toxicities. ${ }^{26-28}$

However, there has been only one study thus far evaluating the safety and efficacy of ${ }^{131}$ I-tositumomab therapy as a single agent in patients with previously untreated stage III/IV follicular lymphoma. ${ }^{29}$ Seventy-six such patients received a dosimetric dose of tositumomab and ${ }^{131}$ I-labeled tositumomab followed 1 week later by a therapeutic dose delivering $75 \mathrm{cGy}$ of radiation to the total body. The overall response rate was $95 \%$ with a $\mathrm{CR}$ of $75 \%$. After a median follow-up of 5.1 years, the actuarial 5-year progression-free survival for all patients was $59 \%$ with a median progression-free survival of 6.1 years. The use of polymerase chain reaction to detect rearrangement of the $B C L 2$ gene showed molecular responses in $80 \%$ of assessable patients who had a clinical CR. Of 57 patients who had a CR, 40 remained in remission for 4.3 to 7.7 years. Hematologic toxicity was moderate with no patient requiring transfusions or hematopoietic growth factors. No cases of myelodysplastic syndrome (MDS) have been observed to date. This study concluded that a single 1-week course of ${ }^{131} \mathrm{I}$-tositumomab as initial treatment can induce prolonged clinical and molecular remissions in patients with advanced follicular lymphoma. Future phase III evaluations will be needed to see if this therapy is able to prolong survival as well.

\section{${ }^{90}$ Y-ibritumomab tiuxetan}

A phase II trial of rituximab and short duration chemotherapy followed by ${ }^{90}$ Y-ibritumomab tiuxetan as first-line treatment for patients with follicular lymphoma has been conducted by the Minnie Pearl Cancer Research Network. ${ }^{30}$ Thirty-three patients with a median age of 56 years and 54\% with stage IV disease were enrolled. Prior to ${ }^{90}$ Y-ibritumomab tiuxetan, 27 of 28 patients (96\%) had objective responses (9 CRs). All patients completing CHOP-Rituxan were eligible for RIT. Twenty-two patients completed therapy and, of these, $19(86 \%)$ were CR and 3 were PR. No unexpected toxicity was seen during CHOP-Rituxan therapy. Hematologic toxicity with ${ }^{90}$ Y-ibritumomab tiuxetan was grade 4 neutropenia in $18 \%$ and grade 4 thrombocytopenia in $0 \%$ of the patients.

\section{Use of RIT in Other Types of Lymphoma}

CD20 expression is noted in many subtypes of lymphoma, not just follicular or transformed disease. Therefore, RIT has been tried in other types of NHL including diffuse large B cell lymphoma and mantle cell lymphoma among others. A recent study evaluated initial treatment of mantle cell lymphoma with sequential RIT with ${ }^{131} \mathrm{I}$-tositumomab followed by CHOP chemotherapy. ${ }^{31}$ Of the 13 patients enrolled, median age was 68 years and overall response rate was $75 \%$. All were $\mathrm{CR}$. There were 5 episodes of febrile neutropenia during the CHOP chemotherapy which was similar to that expected for this older population of patients. There were three relapses at 6,9 and 12 months post completion of therapy and median duration of response has not been reached. Less encouraging results were seen in 15 patients with relapsed/refractory mantle cell lymphoma patients treated with ${ }^{90}$ Y-ibritumomab tiuxetan. Here a response rate of $33 \%$ was noted and patients who had received one or two prior chemotherapeutic regimens had a higher response than those who had received more than three prior regimens $(67 \%$ vs. $11 \%, P<0.001) .32$

\section{Hematopoietic Stem Cell Transplantation (HSCT) in Combination With RIT}

A phase I/II trial was conducted to estimate the maximum tolerated dose of ${ }^{131}$ I-tositumomab that could be combined with etoposide and cyclophosphamide followed by autologous stem cell transplantation in 52 patients with relapsed B cell lymphomas. The estimated overall survival and progression-free survival of all treated patients at 2 years was $83 \%$ and $68 \%$, respectively. These numbers were superior to nonrandomized comparable group of patients treated with total body irradiation in lieu of ${ }^{131}$ I-tositumomab, etoposide and cyclophosphamide. ${ }^{33}$ Another study from the same institution compared 125 patients with follicular lymphoma treated with high-dose RIT using ${ }^{131}$ I-tositumomab to a historical control group of patients treated with conventional high-dose therapy and autologous hematopoietic stem cell transplantation. ${ }^{34}$ The two groups were similar except for the high-dose RIT patients who had slightly higher lactose dehydrogenase levels and international prognostic scores. The estimated 5-year overall survival and progression-free survival were $67 \%$ and $48 \%$, respectively for high-dose RIT, and $53 \%$ and $29 \%$, respectively for conventional high-dose therapy. One hundred-day treatment-related mortality was $3.7 \%$ in the high-dose RIT group and $11 \%$ in the conventional high-dose therapy group. The probability of secondary MDS/acute myeloid leukemia (AML) was estimated to be 0.076 at 8 years in the high-dose RIT group and 0.086 at 7 years in the conventional high-dose therapy group.

The University of Michigan evaluated all patients from 1992-2001 who previously had therapy with ${ }^{131}$ I-tositumomab and then had undergone HSCT for relapsed disease. ${ }^{35}$ In all, 12 patients relapsing after ${ }^{131} \mathrm{I}$-tositumomab had undergone HSCT. Two of these 12 also had a diagnosis of therapy-related myelodysplasia. Most of these patients showed prompt engraftment, but six patients relapsed, including all five autologous and one allogeneic recipient. Four patients were alive with no evidence of disease at the time this abstract was published. Three allogeneic recipients died either from graft-versus-host-disease, relapse or acetaminophen-induced hepatic necrosis. This study demonstrated the feasibility of allogeneic or autologous HSCT in heavily pretreated lymphoma patients who also received ${ }^{131}$ I-tositumomab.

There is one ongoing phase I trial of dose-escalated ${ }^{90}$ Y-ibritumomab tiuxetan followed by BCNU, etoposide, cytarabine and melphalan (BEAM) chemotherapy and autologous stem cell transplant in patients with 
refractory/relapsed CD20+ NHL. ${ }^{36}$ Twenty-eight patients have been enrolled thus far and five patients have safely received ${ }^{90}$ Y-ibritumomab tiuxetan doses at $\geq 0.5 \mathrm{mCi} / \mathrm{kg}$. Formal results from this study are pending at this time.

\section{Other Pertinent Issues Related to RIT}

Incidence of $M D S / A M L$

A retrospective study evaluating the incidence of MDS/AML in 773 patients enrolled in seven studies utilizing ${ }^{131}$ I-tositumomab has been reported. ${ }^{37}$ All these patients had $\leq 25 \%$ bone marrow involvement and received a $65 \mathrm{cGy}$ or $75 \mathrm{cGy}$ total body radiation dose. There were a total of 20 confirmed cases of MDS $(\mathrm{n}=17)$ and AML $(\mathrm{n}=3)$. The annualized incidence for the 773 patients was $1.45 \%$ year. Twelve of the 20 patients had cytogenetic testing. Eleven of 12 patients had at least one abnormal or loss of chromosomes 5 or 7. Overall, the incidence rates of MDS/AML following targeted systemic radiation with ${ }^{131}$ I-tositumomab are consistent with those reported from their pre-131I-tositumomab chemotherapy and radiation. Another group evaluated the incidence of MDS/AML in patients with NHL treated with ${ }^{90}$ Y-ibritumomab tiuxetan and found that 10 of 770 patients over the past 9 years had developed MDS or AML after therapy. ${ }^{38}$ Annualized rates for the development of MDS or AML were $0.21 \%$ and $0.62 \%$ per year, respectively. Most patients displayed multiple cytogenetic aberrations, especially involving chromosomes 5 and 7, similar to those seen after treatment with ${ }^{131} \mathrm{I}$-tositumomab.

\section{RIT in elderly patients}

Elderly patients with NHL may have additional co-morbidities and poor functional status limiting the use of chemotherapy or combined modality therapies. Multiple studies have now evaluated the safety and efficacy of ${ }^{131}$ I-tositumomab and ${ }^{90}$ Y-ibritumomab tiuxetan in these elderly patients. One group evaluated 269 elderly patients, median age 69 years treated with ${ }^{131}$ I-tositumomab. ${ }^{39}$ Forty percent of the patients had bone marrow involvement and $72 \%$ had low-grade NHL and $28 \%$ had transformed low-grade NHL. The patients received a patient-specific total body absorbed radiation dose of $65 \mathrm{cGy}$ or 75 cGy based on platelet count. Grade 4 neutropenia occurred in $16 \%$ and grade 4 thrombocytopenia in $2 \%$ of patients. Supportive care was used in $23 \%$ of patients in the form of growth factors, transfusions and antibiotics. In general, these elderly patients tolerated RIT well. It was thought that specific age-related dose adjustments were not required.

The same group performed a follow-up study and stratified patients by age ( 61 to 70 years, $n=250 ;>70$ years, $n=159)$ and compared them with younger patients $<60$ years $(\mathrm{n}=586) .40$ Patients $>60$ years more frequently had transformed histology, prior radiation therapy and a modified international prognostic index score of 3 to $5(P<0.001)$. Grade $3 / 4$ neutropenia occurred in $44.4 \%$ of younger patients, $36.4 \%$ of patients age 61 to 70 years and $36.3 \%$ of patients age $>70$ years. Grade 3/4 thrombocytopenia occurred in $41.4 \%$ of patients age $<60$ years, $32.8 \%$ of patients age 61 to 70 years and $29.1 \%$ of patients age $>70$ years. About $30 \%$ of patients in each arm required some hematologic supportive care in the form of growth factors or transfusions. Serious hemorrhagic events occurred in $\leq 2.5 \%$ of patients in each group. Overall, infections were more common in younger patients $(P=0.004)$, but serious infections such as sepsis or pneumonia occurred more often in older patients $(P=0.02)$.

\section{RIT and the Relationship to the Degree of Bone Marrow Involvement}

RIT with ${ }^{90}$ Y-ibritumomab tiuxetan and ${ }^{131} \mathrm{I}$-tositumomab has elicited good response rates in patients with relapsed/refractory or newly diagnosed, low- to intermediate-grade NHL. Unfortunately, marrow suppression is the dose limiting toxicity with neutropenia and thrombocytopenia in most patients. In most studies patients with $\geq 25 \%$ bone marrow involvement lymphoma (assessed by bilateral posterior iliac crest core biopsies) were excluded because of concern for potential radiation damage to normal marrow progenitor cells as a result of crossfire from RIT-bound lymphoma cells. One group recently evaluated the relationship between bone marrow involvement and hematologic toxicity in 368 patients with NHL treated with ${ }^{131}$ I-tositumomab. ${ }^{41}$ They found a dose-dependent degree of toxicity with patients having $0 \%$ bone marrow disease (there was $15 \%$ grade 4 neutropenia and $11 \%$ grade 4 thrombocytopenia). In patients with $20 \%$ to $25 \%$ bone marrow involvement, $41 \%$ patients had grade 4 neutropenia and $23 \%$ had grade 4 thrombocytopenia.

In a more recent study, 11 patients with $>25 \%$ bone marrow involvement and platelet count of $\geq 150,000 / \mathrm{mm}^{3}$ were administered patient-specific doses of ${ }^{131} \mathrm{I}$-tositumomab. ${ }^{42}$ Median bone marrow involvement was $40 \%$ and a patient specific dose of ${ }^{131} \mathrm{I}$-tositumomab was administered to deliver a total body dose between 45 cGy and 55 cGy. Dose limiting toxicity was hematologic with $27 \%$ of patients requiring hematologic supportive care. Two patients had a median duration of response of 1 and $\geq 43.6$ months. The authors concluded that patients with $>25 \%$ bone marrow involvement could tolerate $45 \mathrm{cGy}$ total body dose of ${ }^{131} \mathrm{I}$-tositumomab and have a reasonable response to the same.

\section{Future Directions for RIT}

Non-Cellular Targets: Anti-Tenascin Antibody

It has been demonstrated that there is a significantly increased expression of extracellular matrix protein tenascin-C in patients with NHL. This increased stromal expression correlates with increased angiogenesis and blood vessel immaturity leading to increased resistance and disease progression. The enhanced expression of tenascin in diffuse and aggressive lymphomas has prompted the evaluation of radiolabeled therapy directed at this stromal component, especially in patients who have failed treatments directed at differentiation antigens on tumor cells themselves. Rizzieri et al. ${ }^{43}$ recently evaluated the pharmacokinetics, dosimetry, toxicity, and response in 9 patients who were administered radiolabeled antibody directed toward tenascin-C, ${ }^{131}$ I-labeled chimeric 81C6 monoclonal antibody. The mean whole-body effective half-life for ${ }^{131}$ I-labeled chimeric 81C6 monoclonal 
antibody of 110 hours was similar to that for ${ }^{131}$ I-rituximab of 88 hours and longer than that of ${ }^{131}$ I-tositumomab of 56 hours. This prolonged half life may be encouraging in terms of attacking tumor cells but may also cause damage to normal organ tissue leading to significant hematologic side effects which may be dose limiting. It was also noted that this monoclonal antibody had rapid uptake in the liver and marrow and a slower, but enhanced uptake in selected tumors sites over normal tissue. Currently, this form of therapy directed against the tumor stroma remains investigational with aims at minimizing toxicity to normal viscera.

\section{Pretargeted RIT}

In order to increase the efficacy of RIT, pretargeting mechanisms have been devised whereby the tumor is pretargeted with an antibody construct that has affinity for the tumor-associated antigen and for a radiolabeled hapten. Weiden et al. ${ }^{44}$ conducted a pilot study in 10 patients with NHL who had failed all previous therapy including rituximab and Bexxar. In this study, rituximab was conjugated to a tetravalent streptavidin molecule, infused intravenously and followed 1 to 2 days later by a proprietary biotinylated, $\mathrm{N}$-acetylgalactosamine-containing a "clearing agent" that removes surplus antibody from the bloodstream. Three hours later therapeutic ${ }^{90}$ Y-biotin was administered. Four of 7 patients receiving $30 \mathrm{mCi}$ to $50 \mathrm{mCi}$ of ${ }^{90}$ Y-biotin achieved objective remission, including two CRs. This was followed by a phase I study in 15 patients using anti-CD20-streptavidin fusion protein (B9E9FP) as the targeting moiety in order to define its pharmacokinetics and immunogenicity. ${ }^{45}$ B9E9FP was found to have a mean plasma half-life of $25 \pm 6$ hours with 95\% clearance within 6 hours of administering the clearing agent. No significant hematologic toxicities were noted in 12 patients, but 2 patients had hematologic toxicity attributed to progressive disease, 2 patients were CR and 1 patient was PR.

\section{Other Antigenic Targets}

A number of B-lymphocyte antigens other than CD20 have recently been evaluated as targets for immunotherapy in NHL. These antigens include CD22, CD52, CD30, CD80 and HLA-DR and have been thought to be useful in patients who may exhibit resistance against rituximab (anti-CD20). Epratuzumab is the humanized version of LL2, the IgG antibody directed against the CD22 antigen. This antibody is rapidly internalized after attachment to CD22 and it binds minimally to normal tissues other than the spleen. ${ }^{46}$ Epratuzumab has been evaluated as a single agent and in combination with rituximab in patients with relapsed/refractory NHL. One of the first studies that evaluated antibody distribution, pharmacokinetics, dosimetry, toxicity and tumor targeting of ${ }^{131} \mathrm{I}$-labeled LL2-anti-CD22 antibody in 16 patients with relapsed NHL showed tumor responses even with small doses of the drug. ${ }^{47}$ In a Dutch study, 18 patients with relapsed/refractory CD22+ NHL were imaged with technetium-99 (99mTc)-labeled epratuzumab, followed by RIT with ${ }^{186} \mathrm{Re}$-epratuzumab a week later. ${ }^{48}$ Myelosuppression was the dose limiting toxicity seen in most patients. One patient had
CR, 4 patients had PR, 4 had stable disease and 6 patients progressed after RIT. More recently it has been demonstrated that ${ }^{90}$ Y-labeled LL2 anti-CD22 antibody resulted in more favorable tumor dosimetry when compared to ${ }^{131}$ I-labeled LL2 anti-CD22 antibody. 49

Other agents that have been evaluated in NHL include anti-CD80 and anti-CD52 monoclonal antibodies (CAMPATH-1H). All these new antigenic targets have shown promise in preliminary studies but need to be evaluated in larger clinical trials and in combination with radioisotopes.

\section{Conclusion}

RIT combines the benefits of immunotherapy and radioisotopes and has been shown to be effective therapy for NHL, both in relapsed/refractory cases and in newly diagnosed patients. While initial success was found with low-grade NHL, recent studies have shown promising results in other subtypes of lymphoma, even patients with mantle cell and aggressive diffuse large cell disease. ${ }^{131} \mathrm{I}$-tositumomab and ${ }^{90}$ Y-ibritumomab tiuxetan have also been safely used as a conditioning regimen in conjunction with chemotherapy for patients undergoing HSCT and have been shown to be superior to total body irradiation. While initial studies excluded patients with $>25 \%$ bone marrow involvement, there are ongoing studies utilizing RIT in this group of patients to produce a durable response. The main concern with toxicity has been myelosuppression and treatment-induced MDS and one must continue to monitor these patients long after treatment is completed. Other recent developments have included using radioisotopes other than ${ }^{131} \mathrm{I}$ and ${ }^{90} \mathrm{Y}$ utilizing cellular targets like tenascin and utilizing other target antigens on B cells like CD22. These preliminary studies need to be evaluated in larger, prospective, randomized studies for the treatment of NHL. The future of lymphoma therapy will realize a broader use of RIT utilizing different radiolabeled moieties and targets for a greater array of lymphoma subtypes.

\section{References}

1. Jemal A, Tiwari RC, Murray T, Ghafoor A, Samuels A, Ward E, Feuer EJ, Thun MJ; American Cancer Society. Cancer statistics, 2004. CA Cancer J Clin 2004;54:8-29.

2. Greiner TC, Medeiros LJ, Jaffe ES. Non-Hodgkin's lymphoma. Cancer 1995;75:370-380.

3. Press OW. Radioimmunotherapy for non-Hodgkin's lymphomas: a historical perspective. Semin Oncol 2003;30:10-21.

4. Press OW, Rasey J. Principles of radioimmunotherapy for hematologists and oncologists. Semin Oncol 2000;27:62-73.

5. Press OW, Shan D, Howell-Clark J, Eary J, Appelbaum FR, Matthews D, King DJ, Haines AM, Hamann P, Hinman L, Shochat D, Bernstein ID. Comparative metabolism and retention of iodine-125, yttrium-90, and indium-111 radioimmunoconjugates by cancer cells. Cancer Res 1996;56:2123-2129.

6. Macardle PJ, Nicholson IC. CD20. J Biol Regul Homeost Agents 2002;16:136-138.

7. Conry RM, Khazaeli MB, Saleh MN, Ghetie V, Vitetta ES, Liu T, LoBuglio AF. Phase I trial of an anti-CD19 deglycosylated ricin A chain immunotoxin in non-Hodgkin's lymphoma: effect of an intensive schedule of administration. J Immunother Emphasis Tumor Immunol 1995;18:231-241. 
8. Uckun FM, Yanishevski Y, Tumer N, Waurzyniak B, Messinger Y, Chelstrom LM, Lisowski EA, Ek O, Zeren T, Wendorf H, Langlie MC, Irvin JD, Myers DE, Fuller GB, Evans W, Gunther R. Pharmacokinetic features, immunogenicity, and toxicity of B43(anti-CD19)-pokeweed antiviral protein immunotoxin in cynomolgus monkeys. Clin Cancer Res 1997;3:325-337.

9. Shan D, Press OW. Constitutive endocytosis and degradation of CD22 by human B cells. J Immunol 1995;154:4466-4475.

10. Kaminski MS, Fig LM, Zasadny KR, Koral KF, DelRosario RB, Francis IR, Hanson CA, Normolle DP, Mudgett E, Liu CP, Moon S, Scott P, Miller RA, Wahl RL. Imaging, dosimetry, and radioimmunotherapy with iodine 131-labeled anti-CD37 antibody in B-cell lymphoma. J Clin Oncol 1992;10:1696-1711.

11. Wahl RL. The clinical importance of dosimetry in radioimmunotherapy with tositumomab and iodine I 131 tositumomab. Semin Oncol 2003;30:31-38.

12. Cheson B. Bexxar (Corixa/GlaxoSmithKline). Curr Opin Investig Drugs 2002;3:165-170.

13. Rutar FJ, Augustine SC, Kaminski MS, Wahl RL, Siegel JA, Colcher D. Feasibility and safety of outpatient Bexxar therapy (tositumomab and iodine I 131 tositumomab) for nonHodgkin's lymphoma based on radiation doses to family members. Clin Lymphoma 2001;2:164-172.

14. Wiseman GA, White CA, Witzig TE, Gordon LI, Emmanouilides C, Raubitschek A, Janakiraman N, Gutheil J, Schilder RJ, Spies S, Silverman DH, Grillo-Lopez AJ. Radioimmunotherapy of relapsed non-Hodgkin's lymphoma with zevalin, a 90Y-labeled anti-CD20 monoclonal antibody. Clin Cancer Res 1999;5:3281s-3286s.

15. DeNardo GL, Kukis DL, Shen S, DeNardo DA, Meares CF, DeNardo SJ. 67Cu-versus 131I-labeled Lym-1 antibody: comparative pharmacokinetics and dosimetry in patients with non-Hodgkin's lymphoma. Clin Cancer Res 1999;5:533-541.

16. Kennel SJ, Chappell LL, Dadachova K, Brechbiel MW, Lankford TK, Davis IA, Stabin M, Mirzadeh S. Evaluation of 225Ac for vascular targeted radioimmunotherapy of lung tumors. Cancer Biother Radiopharm 2000;15:235-244.

17. Kennel SJ, Stabin M, Roeske JC, Foote LJ, Lankford PK, Terzaghi-Howe M, Patterson H, Barkenbus J, Popp DM, Boll R, Mirzadeh S. Radiotoxicity of bismuth-213 bound to membranes of monolayer and spheroid cultures of tumor cells. Radiat Res 1999;151:244-256.

18. Adelstein SJ, Kassis AI, Bodei L, Mariani G. Radiotoxicity of iodine-125 and other auger-electron-emitting radionuclides: background to therapy. Cancer Biother Radiopharm 2003;18:301-316.

19. Kaminski MS, Estes J, Zasadny KR, Francis IR, Ross CW, Tuck M, Regan D, Fisher S, Gutierrez J, Kroll S, Stagg R, Tidmarsh G, Wahl RL. Radioimmunotherapy with iodine (131)I tositumomab for relapsed or refractory B-cell non-Hodgkin lymphoma: updated results and long-term follow-up of the University of Michigan experience. Blood 2000;96:1259-1266.

20. Vose JM, Wahl RL, Saleh M, Rohatiner AZ, Knox SJ, Radford JA, Zelenetz AD, Tidmarsh GF, Stagg RJ, Kaminski MS. Multicenter phase II study of iodine-131 tositumomab for chemotherapy-relapsed/refractory low-grade and transformed low-grade B-cell non-Hodgkin's lymphomas. J Clin Oncol 2000;18:1316-1323

21. Kaminski MS, Zelenetz AD, Press OW, Saleh M, Leonard J, Fehrenbacher L, Lister TA, Stagg RJ, Tidmarsh GF, Kroll S, Wahl RL, Knox SJ, Vose JM. Pivotal study of iodine I 131 tositumomab for chemotherapy-refractory low-grade or transformed low-grade B-cell non-Hodgkin's lymphomas. J Clin Oncol 2001;19:3918-3928.
22. Knox SJ, Goris ML, Trisler K, Negrin R, Davis T, Liles TM, Grillo-Lopez A, Chinn P, Varns C, Ning SC, Fowler S, Deb N, Becker M, Marquez C, Levy R. Yttrium-90-labeled anti-CD20 monoclonal antibody therapy of recurrent B-cell lymphoma. Clin Cancer Res 1996;2:457-470.

23. Witzig TE, White CA, Wiseman GA, Gordon LI, Emmanouilides C, Raubitschek A, Janakiraman N, Gutheil J, Schilder RJ, Spies S, Silverman DH, Parker E, Grillo-Lopez AJ. Phase I/II trial of IDEC-Y2B8 radioimmunotherapy for treatment of relapsed or refractory CD20(+) B-cell non-Hodgkin's lymphoma. J Clin Oncol 1999;17:3793-3803.

24. Witzig TE, Flinn IW, Gordon LI, Emmanouilides C, Czuczman MS, Saleh MN, Cripe L, Wiseman G, Olejnik T, Multani PS, White CA. Treatment with ibritumomab tiuxetan radioimmunotherapy in patients with rituximab-refractory follicular non-Hodgkin's lymphoma. J Clin Oncol 2002;20:3262-3269.

25. Witzig TE, Gordon LI, Cabanillas F, Czuczman MS, Emmanouilides C, Joyce R, Pohlman BL, Bartlett NL, Wiseman GA, Padre N, Grillo-Lopez AJ, Multani P, White CA Randomized controlled trial of yttrium-90-labeled ibritumomab tiuxetan radioimmunotherapy versus rituximab immunotherapy for patients with relapsed or refractory low-grade, follicular, or transformed B-cell non-Hodgkin's lymphoma. J Clin Oncol 2002;20:2453-2463.

26. Link B, Kaminiski MS, Coleman M, Leonard JP. Phase II study of CVP followed by tositumomab and iodine I 131 tositumomab (Bexxar therapeutic regimen) in patients with untreated follicular non-Hodgkin's lymphoma (NHL). J Clin Oncol 2004;22(14S):abstract 6520.

27. Leonard JP, Coleman M, Kostakoglu L, Chadburn A, Cesarman E, Hack S, Kroll SM, Tidmarsh G, Vallabhajosula S, Goldsmith SJ. Triple modality therapy for follicular low-grade lymphoma: initial treatment with fludarabine followed by Bexxar ${ }^{\mathrm{TM}}$. Am Soc Hematol 2001; abstract 3505.

28. Press OW, Unger JM, Braziel RM, Maloney DG, LeBlanc ML,Grogan TM, Miller TP, Fisher RI. A phase II trial of CHOP followed by Bexxar ${ }^{\mathrm{TM}}$ (tositumomab and iodine-131-tositumomab) for treatment of newly diagnosed follicular non-Hodgkin's lymphomas (SWOG 9911) Am Soc Hematol 2001;abstract 3504.

29. Kaminski MS, Tuck M, Estes J, Kolstad A, Ross CW, Zasadny K, Regan D, Kison P, Fisher S, Kroll S, Wahl RL. 131I-tositumomab therapy as initial treatment for follicular lymphoma. N Engl J Med 2005;352:441-449.

30. Shipley DL, Spigel DR, Carrell DL, Dannaher C, Greco FA, Hainsworth JD. Phase II trial of rituximab and short duration chemotherapy followed by ${ }^{90}$ Y-ibritumomab tiuxetan as first-line treatment for patients with follicular lymphoma: A Minnie Pearl Cancer Research Network phase II trial. J Clin Oncol 2004;22(14S):abstract 6519.

31. Zelenetz AD, Donnelly G, Halaas J, Sgouros G, Humm J, Popplewell L, Reyes S, Maignan K, Campbell C, Moskowitz $\mathrm{CH}$, Nimer SD, Pandit-Taskar N, Divgi C. Initial treatment of mantle cell lymphoma with sequential radioimmunotherapy with tositumoamb/iodine I131 I-tositumoamb followed by CHOP chemotherapy results in a high complete remission rate. Am Soc Hematol 2003; abstract 1477.

32. Oki Y, Pro B, Delpassand E, Ballaster V, McLaughlin P, Romaguera J, Wang M, Hagemeister FB, Younes A. A phase II study of yttrium 90 (90Y) ibritumomab tiuxetan $\left(\right.$ Zevalin $\left.{ }^{\circledR}\right)$ for treatment of patients with relapsed and refractory mantle cell lymphoma (MCL). Am Soc Hematol 2004; abstract 2632. 
33. Press OW, Eary JF, Gooley T, Gopal AK, Liu S, Rajendran JG, Maloney DG, Petersdorf S, Bush SA, Durack LD, Martin PJ, Fisher DR, Wood B, Borrow JW, Porter B, Smith JP, Matthews DC, Appelbaum FR, Bernstein ID. A phase I/II trial of iodine-131-tositumomab (anti-CD20), etoposide, cyclophosphamide, and autologous stem cell transplantation for relapsed B-cell lymphomas. Blood 2000;96:2934-2942.

34. Gopal AK, Gooley TA, Maloney DG, Petersdorf SH, Eary JF, Rajendran JG, Bush SA, Durack LD, Golden J, Martin PJ, Matthews DC, Appelbaum FR, Bernstein ID, Press OW. High-dose radioimmunotherapy versus conventional high-dose therapy and autologous hematopoietic stem cell transplantation for relapsed follicular non-Hodgkin lymphoma: a multivariable cohort analysis. Blood 2003;102:2351-2357.

35. Ratanatharathorn V, Uberti JP, Ayash L, Estes J, Silver S, Kaminski M. Hematopoietic stem cell transplantation (HSCT) in lymphoma patients receiving prior therapy with tositumomab and iodine $\mathrm{I}^{131}$ tositumomab (Bexxar $\left.{ }^{\mathrm{TM}}\right)$. Am Soc Hematol 2001; abstract 836.

36. Winter JN, Inwards DJ, Spies S, Wiseman G, Patton D, Erwin W, Rademaker A, Williams SF, Tallman MS, Micallef I, Mehta J, Singhal S, Zimmer M, Molina A, White C, Gordon LI. ${ }^{90}$ Y Ibritumomab tiuxetan (Zevalin $\AA$; ${ }^{90} \mathrm{YZ}$ ) doses higher than $.4 \mathrm{mCi} / \mathrm{kg}$ may be safely combined with high-dose beam and autotransplant: the role for dosimetry. Am Soc Hematol 2004; abstract 1162.

37. Bennett JM, Zelenetz AD, Press OW, Vose JM, Radford JA, Knox SJ, Wilkinson M, Schwartz RS, Kaminski MS, Capizzi $\mathrm{R}$. Incidence of myelodysplastic syndromes (tMDS) and acute myeloid leukemia (tAML) in patients with low-grade non-Hodgkin's lymphoma (LG-NHL) treated with BexxarTM. Am Soc Hematol 2001;abstract 1416.

38. Czuczman M, Witzig TE, Gaston I, Skikne BS, Dimitrov G, Gordon LI, Emmanouilides C, White CA. Zevalin ${ }^{\mathrm{TM}}$ radioimmunotherapy is not associated with an increased incidence of secondary myelodysplastic syndrome (MDS) or acute myelogenous leukemia (AML). Am Soc Hematol 2002; abstract 1386

39. Gregory SA, Coleman M, Dillman RO, Magnuson D, Kaminski MS. Bexxar ${ }^{\mathrm{TM}}$ is a well-tolerated therapy in elderly patients with low-grade or transformed low-grade non-Hodgkin's lymphoma. Am Soc Hematol 2001; abstract 2535.

40. Gregory SA, Zelenetz AD, Knox SJ, Vose JM, Kaminski MS. The BEXXAR therapeutic regimen (tositumomab and iodine I 131 tositumomab) can be safely administered to patients over the age of 70. Am Soc Hematol 2003; abstract 1485.

41. Gregory SA, Leonard J, Coleman M, Zelenetz A, Vose J. Relationship of degree of bone marrow involvement with hematologic toxicity in patients with non-Hodgkin's lymphoma treated with tositumomab and iodine I 131 tositumomab. Proc Am Soc Clin Oncol 2003;22:575 (abstract 2314).

42. Mones J, Coleman M, Kostakoglu L, Fiore JM, Muss D, Furman R, Stewart P, Kroll S, Goldsmith SJ, Leonard JP. A dose-escalation study of tositumomab and iodine I 131 tositumomab (Bexxar) in pts with previously treated non-Hodgkin's lymphoma (NHL) with $>25 \%$ bone marrow involvement. J Clin Oncol 2004;(14S):abstract 6575.

43. Rizzieri DA, Akabani G, Zalutsky MR, Coleman RE, Metzler SD, Bowsher JE, Toaso B, Anderson E, Lagoo A, Clayton S, Pegram CN, Moore JO, Gockerman JP, DeCastro C, Gasparetto C, Chao NJ, Bigner DD. Phase 1 trial study of 131I-labeled chimeric 81C6 monoclonal antibody for the treatment of patients with non-Hodgkin lymphoma. Blood 2004; 104:642-648.

44. Weiden PL, Breitz HB. Pretargeted radioimmunotherapy (PRIT) for treatment of non-Hodgkin's lymphoma (NHL). Crit Rev Oncol Hematol 2001;40:37-51.
45. Forero A, Weiden PL, Vose JM, Knox SJ, LoBuglio AF, Hankins J, Goris ML, Picozzi VJ, Axworthy DB, Breitz HB, Sims RB, Ghalie RG, Shen S, Meredith RF. Phase 1 trial of a novel anti-CD20 fusion protein in pretargeted radioimmunotherapy for B-cell non-Hodgkin lymphoma. Blood 2004;104:227-236.

46. Coleman M, Goldenberg DM, Siegel AB, Ketas JC, Ashe M, Fiore JM, Leonard JP. Epratuzumab: targeting B-cell malignancies through CD22. Clin Cancer Res 2003;9:3991S-3994S.

47. Goldenberg DM, Horowitz JA, Sharkey RM, Hall TC, Murthy S, Goldenberg H, Lee RE, Stein R, Siegel JA, Izon DO, Burger K, Swayne LC, Belisle E, Hansen HJ, Pinsky CM. Targeting, dosimetry, and radioimmunotherapy of B-cell lymphomas with iodine-131-labeled LL2 monoclonal antibody. J Clin Oncol 1991;9:548-564.

48. Postema EJ, Raemaekers JM, Oyen WJ, Boerman OC, Mandigers CM, Goldenberg DM, van Dongen GA, Corstens FH. Final results of a phase I radioimmunotherapy trial using (186)Re-epratuzumab for the treatment of patients with non-Hodgkin's lymphoma. Clin Cancer Res 2003;9:3995S-4002S.

49. Juweid ME, Stadtmauer E, Hajjar G, Sharkey RM, Suleiman S, Luger S, Swayne LC, Alavi A, Goldenberg DM. Pharmacokinetics, dosimetry, and initial therapeutic results with 131I- and (111)In-/90Y-labeled humanized LL2 anti-CD22 monoclonal antibody in patients with relapsed, refractory non-Hodgkin's lymphoma. Clin Cancer Res 1999;5:3292s-3303s.

\section{Author Affiliations}

Arati V. Rao, MD, Division of Medical Oncology and Division of Geriatrics, Duke University Medical Center and Durham Veterans Affairs Medical Center, 508 Fulton Street, Durham, NC 27710

Gamal Akabani, PhD, Department of Radiology, Duke University Medical Center, Durham, NC 27710

David A. Rizzieri, MD, Duke University Medical Center, 2400 Pratt Street, Suite 1100, Durham, NC 27710 